\title{
Research Article \\ Shear Flow Induced Alignment of Carbon Nanotubes in Natural Rubber
}

\author{
Yan He, Zhifang Cao, and Lianxiang Ma \\ College of Mechanic and Electronic Engineering, Qingdao University of Science and Technology, No. 99, Songling Road, \\ Qingdao, Shandong 266061, China
}

Correspondence should be addressed to Zhifang Cao; czfqust@foxmail.com

Received 5 June 2015; Revised 26 August 2015; Accepted 10 September 2015

Academic Editor: Marilyn L. Minus

Copyright (C) 2015 Yan He et al. This is an open access article distributed under the Creative Commons Attribution License, which permits unrestricted use, distribution, and reproduction in any medium, provided the original work is properly cited.

\begin{abstract}
A new procedure for the fabrication of natural rubber composite with aligned carbon nanotubes is provided in this study. The two-step approach is based on (i) the preparation of mixture latex of natural rubber, multiwalled carbon nanotubes, and other components and (ii) the orientation of carbon nanotubes by a flow field. Rubber composite sheets filled with variable volume fraction of aligned carbon nanotubes were fabricated and then confirmed by transmission electron microscopy and Raman spectroscopy studies. An obvious increase in thermal conductivity has been obtained after the alignment of carbon nanotubes. The dynamic mechanical analysis was carried out in a tear mode for the composite.
\end{abstract}

\section{Introduction}

Carbon nanotube (CNT) is a kind of tube-like material which is rather like a rolled-up graphene sheet composed of a hexagonal network of carbon atoms where the internal space is empty. A great deal of attention has been paid on this tiny but fascinating material since it was found by Iijima [1], a scholar on electron microscope of Japan, in 1991. It is reported that it shows a tremendous potential in numerous fields [2-5]. Rubber is a conventional material used widely. In order to achieve optimal enhancement in thermal, electric, and mechanical properties of natural rubber, a lot of improvement approaches have been proposed; among them adding CNTs with excellent properties is an effective way. Peddini et al. [6] researched the morphology and rheology of styrene-butadiene rubber with multiwall carbon nanotubes, and they found that the glass transition temperature of the composite increased $4.5^{\circ} \mathrm{C}$. Wang et al. [7] added CNTs to silicone rubber to improve the material's sensitivity and sensing linearity for pressure. Kueseng et al. [8] obtained composite with high electrical conductivity by adding CNTs to NR/NBR through a two-roll mill, and its maximum damping parameter had also decreased.

Carbon nanotube has an extremely high thermal conductivity, which can reach up to $6600 \mathrm{~W} /(\mathrm{m} \cdot \mathrm{K})$ by theoretical calculation [9], and its experimental thermal conductivity can be over $3000 \mathrm{~W} /(\mathrm{m} \cdot \mathrm{K})[10]$, so it is expected to increase the thermal conductivity of composite drastically. It was reported that the thermal conductivity of composites filled with CNTs can be increased markedly comparing to the matrix material. Hwang et al. [11] focused on enhancing the thermal conductivity of poly(ether-ether-ketone) by adding CNTs. The thermal conductivity of composite they fabricated increased to $0.36 \mathrm{Wm}^{-1} \mathrm{~K}^{-1}$. Heat is transmitted by phonon along the axial direction of the carbon nanotubes, showing obvious directivity [12]; that is to say, it is hard for heat to pass through a carbon nanotube wall reaching another carbon nanotube. If the CNTs can be oriented in the matrix, it can increase the electric and thermal conductivity of composite effectively, preventing the accumulation of static electricity [13]. Different approaches for aligning carbon nanofillers have been reported in literatures, mainly based on mechanical stretching $[14,15]$ or the application of an electric field [16] or magnetic field [17, 18]. It is a challenge to orient CNTs in matrix material, especially in natural rubber due to its thermosetting property, which limits the movement of CNT even at a high temperature. By utilizing suitable solvent, we got a rubber latex filled with CNTs and then fabricated a natural rubber sheet filled with aligned carbon nanotubes in a controllable direction by a flow field. Vigolo et al. [19] have 


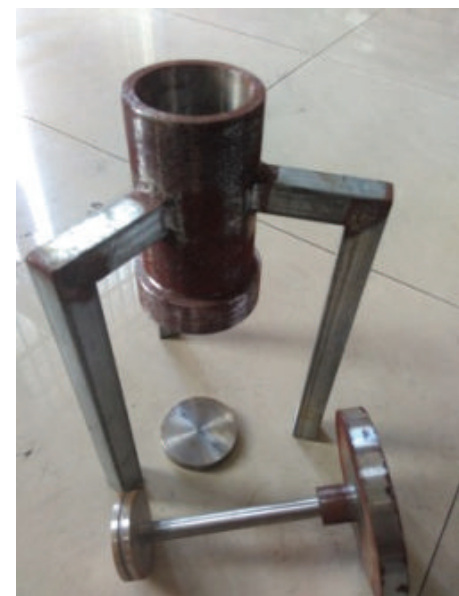

(a)

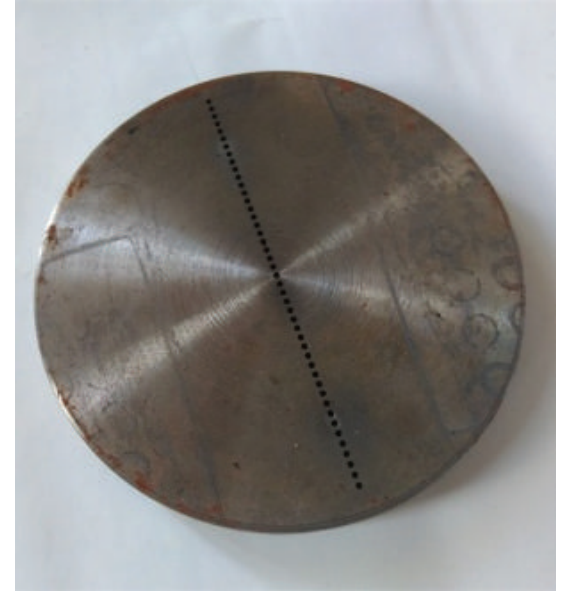

(b)

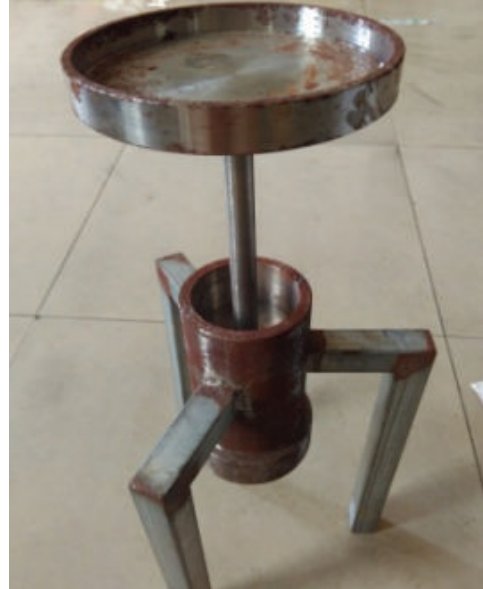

(c)

FIGURE 1: Apparatus used for alignment of CNTs in natural rubber.

successfully aligned CNTs in aqueous solutions of sodium dodecyl sulfate through a flow field caused by injection. To the best of the authors' knowledge, this is the first report on the production of aligned carbon nanotube-filled rubber by a flow field, although there have been a few reports on the alignment of carbon nanotubes in polymers using other methods.

\section{Materials and Methods}

2.1. Materials. MWCNTs with purity $>95 \%$, diameters in range of $40 \sim 60 \mathrm{~nm}$, and length $>5 \mu \mathrm{m}$ were procured from $\mathrm{Na}$ Mi Gang Limited Company of Shenzhen, China. Natural rubber was obtained from Hainan Natural Rubber Industry Group. All other chemicals used were of analytical grade unless otherwise stated.

2.2. Experimental Details. $10 \mathrm{~g}$ of natural rubber was used for each preparation of samples in this experiment, and the other constituents were weighed as shown in Table 1. The natural rubber was dissolved in $200 \mathrm{~mL}$ of methylbenzene for $24 \mathrm{~h}$, and then a kind of rubber latex can be obtained after a period of mechanical agitation. Then a certain number of multiwalled carbon nanotubes (MWCNTs) were dispersed in $75 \mathrm{~mL}$ of methylbenzene by ultrasound for $30 \mathrm{~min}$ at room temperature, which contributed to a stable suspension. Each of the other components showed in Table 1 was also put into $75 \mathrm{~mL}$ of methylbenzene, and followed by this was ultrasonic dispersing for $30 \mathrm{~min}$ at $50^{\circ} \mathrm{C}$, so that a suspension with additives can be obtained. Mix the three reagents mentioned above together in a 3-mouth flask to get a kind of uniform and stable mixture latex, during which the mechanical agitation was needed. The next step was to realize the directional alignment of MWCNTs; for this, the mixture latex containing all components including natural rubber, CNTs, and additives was compelled to pass through a sieve with holes whose diameter is $1 \mathrm{~mm}$, and depth is $12 \mathrm{~mm}$ by pressure. The apparatus was shown in Figure 1; the cavity in picture (a) was
TABLE 1: The composition of composite.

\begin{tabular}{lc}
\hline Constituent & $\mathrm{phr}^{\mathrm{a}}$ \\
\hline Natural rubber & 100 \\
Sulfur (S) & 3 \\
Zinc oxide & 5 \\
Accelerator ZDC & 1 \\
Stearic acid & 2 \\
Antioxidant RD & 1 \\
Ethylxanthic acid potassium salt & 1 \\
MWCNTs & Variate $^{\mathrm{b}}$
\end{tabular}

${ }^{a}$ Per hundred of rubber in quality.

${ }^{\mathrm{b}}$ The amount of the CNTs was determined by its volume fraction, which can be calculated from the equation $M_{\mathrm{CNTs}} / \rho_{\mathrm{CNTs}}=\left(M_{\mathrm{CNTs}} / \rho_{\mathrm{CNTs}}+\right.$ $\left.M_{\mathrm{NR}} / \rho_{\mathrm{NR}}+V_{\mathrm{Add}}\right) \times C \%, C \in(0,2,4,6,8,10)$, where $V_{\text {Add }}$ is the total volume of all the additives used in the formula, and each of them can be got from its quality and density.

used for adding mixture; the part in picture (b) is the core component in which a row of holes was manufactured for convenient operation; the disk over the cavity connected to the plunger was used for load-bearing to provide a constant pressure just as shown in picture (c). So the mixture latex can be extruded through the sieve under pressure. It was reported that there existed a flow field in the fluid passing through a hole [20]. So the MWCNTs can be oriented along the shear force caused by the flow field. The mixture latex passed through the sieve was collected in a mold shown in Figure 2, which was composed of three parts that can be assembled to a rectangular box. A suitable opening can be controlled by different assembling just as shown in pictures (b) and (c). In the experiment, the latex was collected in the opening in picture (b) and then changed its opening to a status in picture (c) to get a sample with CNTs oriented perpendicular to the biggest plane. After that, the latex with 


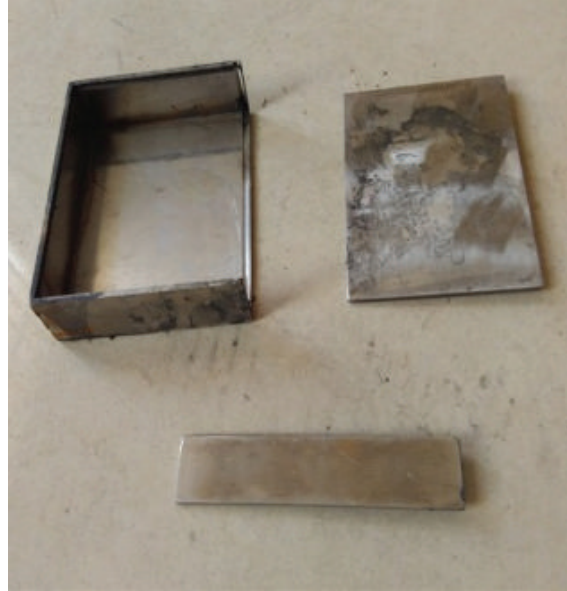

(a)

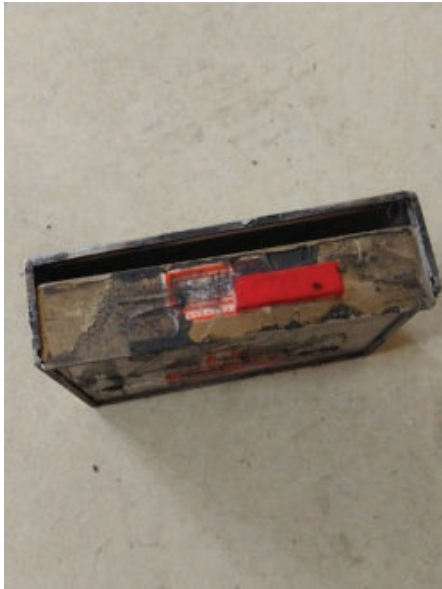

(b)

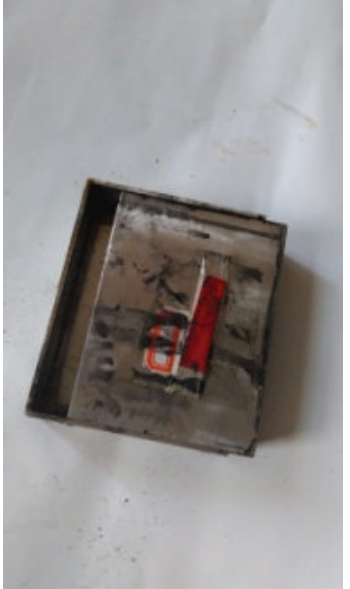

(c)

FIgURE 2: Mold for mixture latex after alignment of CNTs.

oriented MWCNTs was defoamed in vacuum for 30 minutes and then put under a fume cupboard for 24 hours, during which the methylbenzene in the sample could volatilize and the rubber could be cross-linked. So, we could get a sample from the mold for properties testing. For the property comparison of composite with oriented CNTs to the random CNTs, composite with random CNTs was also prepared. Just like the procedure described above, the mixture latex was prepared in the same way; then it was put into a mold directly instead of passing through a sieve with holes. After that, the sample was set in vacuum and then a fume cupboard in the same way. So we can also get a sample of composite with random CNTs.

\section{Results and Discussion}

3.1. Morphology Characterization. The feature of WMCNTs can be observed under transmission electron microscope (TEM). In order to check the dispersion and arrangement of carbon nanotubes in rubber, pictures of samples were taken by transmission electron microscope (JEM-2100, JEOL) at a voltage of $200 \mathrm{kV}$. For this, ultramicrocut with thickness around $50 \mathrm{~nm}$ was made along the direction of shear flow by a cryoultramicrotome. Pictures for samples with different volume fraction of WMCNTs aligned by a flow field and not were shown in Figure 3. Among them, (a) and (c) are ones for composites with filler volume fraction of $2 \%$ and $6 \%$, respectively, whose WMCNTs were not oriented by a flow field. As shown in the pictures, WMCNTs were isotropic and dispersed disorderly without directionality. From the view of WMCNTs length, there are many short WMCNTs or points. They are ones that are perpendicular or nearly perpendicular to the surface of the image, which were cut short during the ultramicrocut section. And (b) and (d) are ones for composites with oriented WMCNTs of 2 vol. \% and 6 vol. \%, respectively, by a shear flow. As shown in the pictures, many of the MWCNTs were in the same direction to a great extent along the arrows in the pictures, distributing along one direction more than its perpendicular direction; at the same time, the chopped MWCNTs significantly reduced in number. It means that the MWCNTs perpendicular to the image surface reduced and they have been arranged substantially in the same direction. It is noteworthy that there was little aggregate in rubber matrix, indicating good dispersion of carbon nanotubes.

3.2. Polarized Raman Characterization. Polarized Raman spectroscopy is a powerful tool for investigating the orientation of CNTs in a polymer matrix by the analysis of intensity variation of the G-band with the variation of angle between the CNT axis and polarization direction of the incident light. The composite with random MWCNTs was isotropous, so the variation of the angle between axis of oriented CNTs and laser source could not cause a change in the intensity of the composite material spectrum [16, 21-24]. However, for the composite with oriented CNTs, it would lead to a significant change in the absorption strength of each characteristic peak. The samples with variable volume fraction of oriented CNTs were characterized through polarized Raman spectrum (by Renishaw inVia) and three samples for each formula were tested. The polarized Raman spectrum of composite filled with 6 vol. \% of oriented MWCNTs was shown in Figure 4, which was stimulated by a laser of $785 \mathrm{~nm}$. The peak around $1310 \mathrm{~cm}^{-1}$ is called D-band, caused by defects located along the nanotube sidewalls [25]. The peak around $1580 \mathrm{~cm}^{-1}$ named as G-band resulted by the elongation of the carboncarbon bonds along the longitudinal axis of the nanotubes [26]. And the peak around $2620 \mathrm{~cm}^{-1}$, called $\mathrm{G}^{\prime}$-band, is known to be an overtone or a second-order harmonic of the D-band. The direction $0^{\circ}$ means that the exciting laser is parallel to the axis of oriented CNTs, which has been determined by polarized Raman testing that the intensity of Raman scattering is maximum. The minimum intensity of Raman scattering can be obtained when the direction is $90^{\circ}$, at which the exciting laser is orthogonal to the axis of oriented CNTs. The ratio $\mathrm{G} 0^{\circ} / \mathrm{G} 90^{\circ}$ of the intensity of peaks at $0^{\circ}$ and $90^{\circ}$ can be used to measure the alignment of carbon nanotubes. In principle, for nanotubes dispersed randomly in 


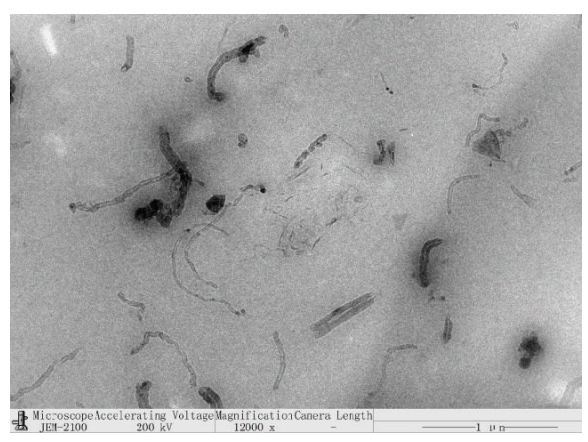

(a)

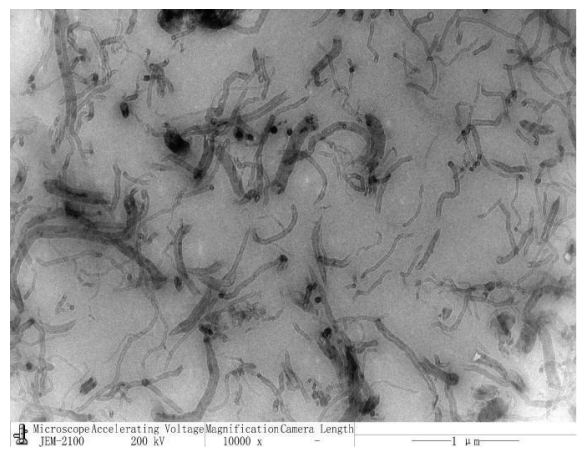

(c)

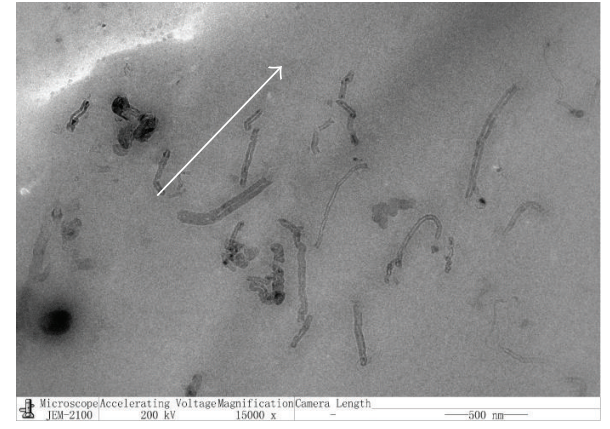

(b)

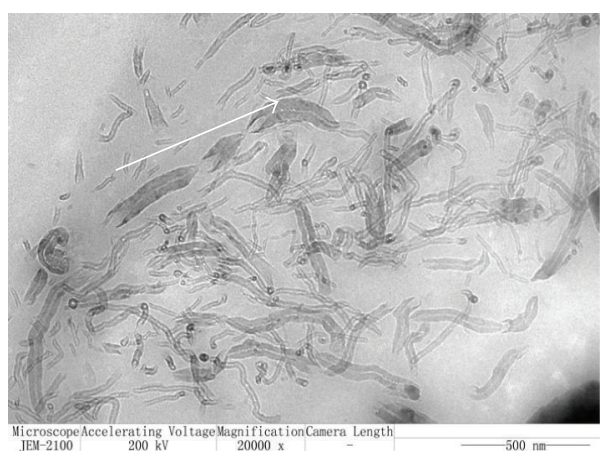

(d)

FIGURE 3: (a) and (c) are TEM images of composite with random MWCNTs at the volume fraction of $2 \%$ and $6 \%$, respectively. (b) and (d) are TEM images of composite containing 2 vol. $\%$ and 6 vol. $\%$ of MWCNTs oriented by a shear flow, respectively.

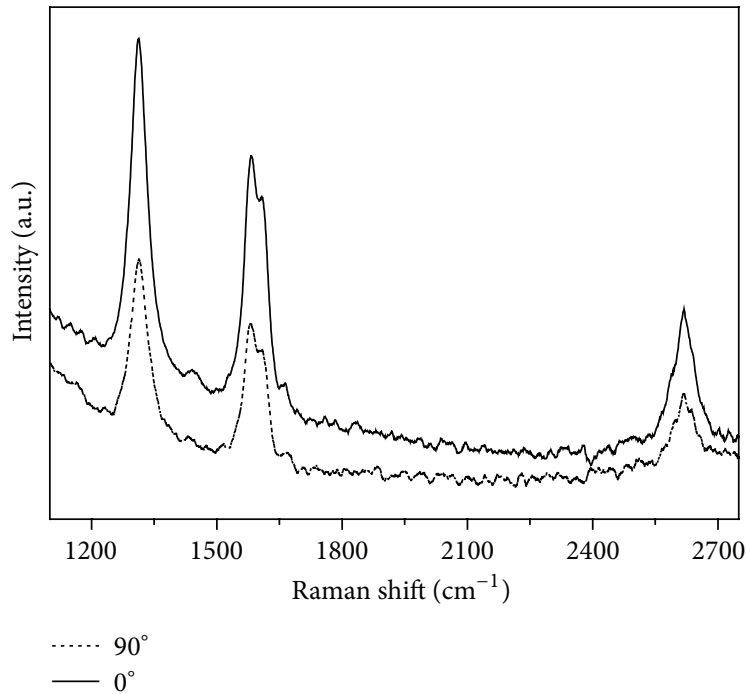

FIgURE 4: Polarized Raman spectra of composite with aligned MWCNTs of 6 vol. \%.

the composite, it should be equal to 1 . The ratio $\mathrm{G} 0^{\circ} / \mathrm{G} 90^{\circ}$ measured from sample is 1.890 , which indicates that the carbon nanotubes are aligned preferentially along a certain direction, in accordance with the result by TEM.

The average $D$ peaks and $G$ peaks intensity of Raman spectra of oriented MWCNTs/NR nanocomposite with different CNT contents were compared in Table 2. As shown
TABLE 2: Raman spectra intensity and its ratio of oriented MWCNTs/NR nanocomposite at different MWCNT contents.

\begin{tabular}{|c|c|c|c|c|c|c|c|}
\hline \multicolumn{3}{|c|}{ Volume fraction (\%) } & 2 & 4 & 6 & 8 & 10 \\
\hline \multirow{6}{*}{ Intensity (a.u.) } & & $\mathrm{D}^{\circ}$ & 3063 & 3136 & 3292 & 3428 & 3842 \\
\hline & D-band & $\mathrm{D} 90^{\circ}$ & 1592 & 1529 & 1622 & 1878 & 1921 \\
\hline & & $\mathrm{D} 0^{\circ} / \mathrm{D} 90^{\circ}$ & 1.924 & 2.05 & 2.030 & 1.825 & 2.000 \\
\hline & \multirow{3}{*}{ G-band } & $\mathrm{G} 0^{\circ}$ & 1369 & 2434 & 2543 & 2608 & 2857 \\
\hline & & $\mathrm{G} 90^{\circ}$ & 863 & 1340 & 1345 & 1569 & 1724 \\
\hline & & $\mathrm{G} 0^{\circ} / \mathrm{G} 90^{\circ}$ & 1.586 & 1.816 & 1.890 & 1.660 & 1.657 \\
\hline
\end{tabular}

in the table, the intensity of the $D$ peaks and $G$ peaks decreases with increasing the polarization angle. And the ratio of $\mathrm{G} 0^{\circ} / \mathrm{G} 90^{\circ}$ is always higher than 1 , as well as the ratio of $\mathrm{D} 0^{\circ} / \mathrm{D} 90^{\circ}$. The obtained $\mathrm{G} 0^{\circ} / \mathrm{G} 90^{\circ}$ ratios are higher than those found in the literature by electric field and magnetic field, which generally do not exceed 1.5 [16, 27]. The peaks generated by CNTs increase in intensity with the increasing of nanotube concentration. This phenomenon was probably due to a thermal effect arising from the absorption in the polymer, because most of the thermal energy was accumulated by nanotubes under the laser beam [28]. The ratio $\mathrm{G} 0^{\circ} / \mathrm{G} 90^{\circ}$ maximized at $6 \%$ concentration and then deteriorated because of the aggregation of CNTs with the increasing of filler concentration above $6 \%$, which was disadvantage to the orientation of CNTs. 


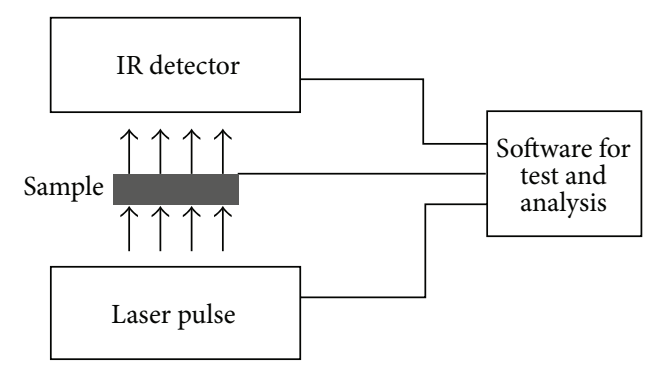

FIGURE 5: Illustration of laser flash analysis technique.

3.3. Thermal Conductivity of Composite. Laser flash analysis (LFA) is currently the most popular method of measuring the thermal conductivity of composite materials. In this method, the thermal conductivity could not be measured directly but could be computed by thermal diffusivity, heat capacity, and density measured. Thermal conductivity measurements were determined using a Netzsch Laser Flash Analysis (LFA 447 ) in our experiment. The lower surface of a plane-parallel sample is heated by a laser pulse, and temperature rise on the top surface is measured using an IR detector as illustrated in Figure 5. In addition to thermal diffusivity, the heat capacity can also be calculated by the heat capacity of a master standard and its ratio of testing sample in the same procedure. The density of samples was measured by an ultramicrodensitometer "ST-XS-365 M." So the thermal conductivity of composite can be calculated by the following formula:

$$
\lambda=\alpha \rho C_{p},
$$

where $\lambda$ is the thermal conductivity, in $\mathrm{Wm}^{-1} \cdot \mathrm{K}^{-1} ; \alpha$ is thermal diffusivity, in $\mathrm{cm}^{2} / \mathrm{s} ; \rho$ is density of samples, in $\mathrm{g} / \mathrm{cm}^{3}$; and $C_{p}$ is heat capacity in $\mathrm{Jkg}^{-1} \mathrm{~K}^{-1}$.

Samples were cut into cylinders in diameter of $12.7 \mathrm{~mm}$ and thickness around $1 \mathrm{~mm}$ and then coated with graphite spray to increase the light absorption and infrared emission of surface. All measurements were taken at room temperature with a laser voltage power of $304 \mathrm{~V}$, a medium pulse with width of $0.18 \mathrm{~ms}$, and a laser transmission filter of $100 \%$. All signal curves were fitted using a Cowan plus impulse correction model. Thermal conductivity of composite with variable volume fraction of MWCNTs aligned by a flow field and not generated from the LFA was illustrated in Figure 4 and the standard deviation was included. The average thermal conductivity of a composite material depends upon the relative contributions of the individual components in each system [29]. As shown in Figure 4, its thermal conductivity increases gradually with the increase of filler volume fraction for both the composites with random MWCNTs and aligned MWCNTs because the more MWCNTs were added in the composite, the more integrated network was formed. And the composite with aligned carbon nanotubes always has a higher thermal conductivity at the same filler volume fraction due to the anisotropy of heat conduction along carbon nanotubes. The thermal conductivity of composite with 10 vol. \% of MWCNTs aligned by a flow field can be

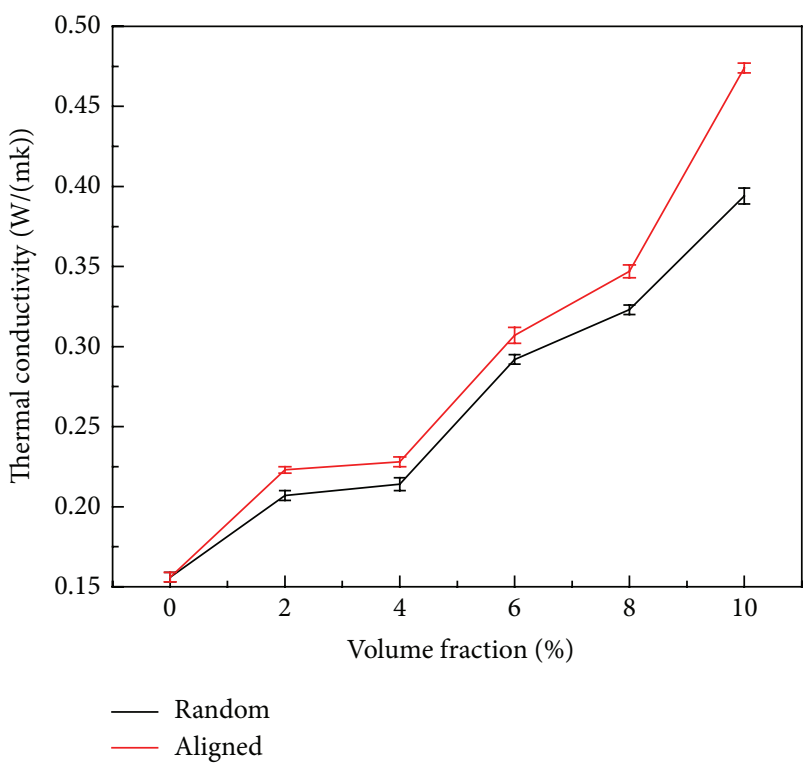

FIgURE 6: Thermal conductivity of composite.

up to $0.475 \mathrm{Wm}^{-1} \mathrm{k}^{-1}$, which shows an enormous superiority comparing to natural rubber filled with carbon black at the same filler concentration, whose thermal conductivity was $0.22 \mathrm{Wm}^{-1} \mathrm{k}^{-1}$ at filling concentration of $10 \mathrm{vol}$. \% [30]. The thermal conductivity increased by $19.1 \%$ comparing with the composite with random MWCNTs at the same filling factor and increased by $129 \%$ comparing with the matrix material without MWCNTs added. The thermal conductivity of composite fabricated in this method is generally higher than or comparable to that of other polymers with CNTs [3133], in spite of the lower thermal conductivity of pure natural rubber (Figure 6).

3.4. Mechanical Characterization. Carbon nanotubes can always improve the mechanical properties of composite greatly due to its extremely high modulus and strength [34, 35]. In order to investigate the effect of alignment of MWCNTs on the composite, dynamic mechanical analysis (DMA) tests (by Dynamic Mechanical Analyzer from METTLERTOLEDO) have been carried out both on composite with aligned MWCNTs and on composite with random MWCNTs. Samples were cut into dimensions of $4 \mathrm{~mm} \times 4 \mathrm{~mm}$, and their thickness was around $1 \mathrm{~mm}$, but their accurate value was obtained by a thickness gauge as an input variable for DMA. For this, the axis of the oriented MWCNTs was perpendicular to the plane of $4 \mathrm{~mm} \times 4 \mathrm{~mm}$; that means the shear force was perpendicular to axis of the oriented MWCNTs in the testing. The dynamic mechanical behavior of composite has been obtained by a shear mode at $10 \mathrm{~Hz}$ and a heating scan of $3^{\circ} \mathrm{C} / \mathrm{min}$, which was reported in Figure 7 and Table 3 .

In Figure 7, dynamic mechanical behavior of composite with 10 vol. \% of MWCNTs oriented by a flow field and not, the curves of storage modulus $M^{\prime}$ scaled by the left scale, and loss factor $\tan \delta$ scaled by the right scale are included in the figure. As shown, the alignment of MWCNTs can increase 
TABLE 3: Dynamic mechanical properties of composite with different MWCNT contents.

\begin{tabular}{lcccc}
\hline $\begin{array}{l}\text { Volume } \\
\text { fraction } \\
(\%)\end{array}$ & Aligned or not & Modulus $M^{\prime \mathrm{a}} / \mathrm{MPa}$ & $T_{g}{ }^{\mathrm{b}} /{ }^{\circ} \mathrm{C}$ & $\tan \delta_{\max }$ \\
\hline 0 & - & 530.9 & -43.1 & 1.566 \\
\hline \multirow{2}{*}{2} & $\mathrm{~N}$ & 599.8 & -41.7 & 1.476 \\
& $\mathrm{Y}$ & 701.1 & -42.1 & 1.453 \\
\hline \multirow{2}{*}{4} & $\mathrm{~N}$ & 727.1 & -41.6 & 1.447 \\
& $\mathrm{Y}$ & 895.6 & -42.2 & 1.378 \\
\hline 6 & $\mathrm{~N}$ & 831.6 & -40.5 & 1.160 \\
& $\mathrm{Y}$ & 946.0 & -41.6 & 1.113 \\
\hline \multirow{2}{*}{10} & $\mathrm{~N}$ & 979.2 & -41.2 & 1.085 \\
& $\mathrm{Y}$ & 1194.3 & -41.8 & 1.021 \\
\hline
\end{tabular}

${ }^{\mathrm{a}}$ Maximum storage modulus of composite.

${ }^{\mathrm{b}}$ Treat the temperature at which the curve of loss factor $(\tan \delta)$ gets a peak as glass transition temperature.

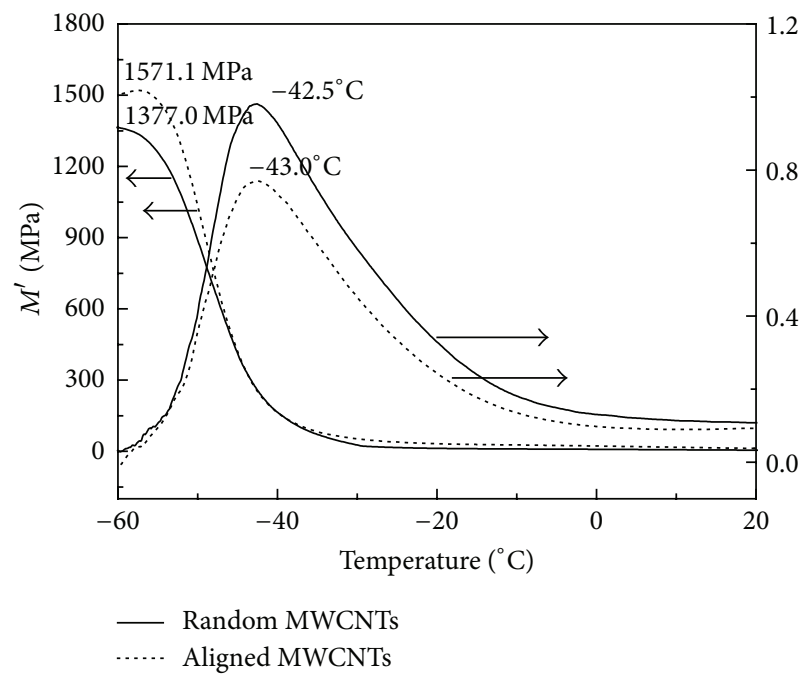

Figure 7: Dynamic mechanical behavior of composite with 10 vol. $\%$ of MWCNTs oriented by a flow field and not. Storage modulus $M^{\prime}$ and loss factor $\tan \delta$ are included.

the maximum storage modulus of composite dramatically (from 1377.0 MPa to 1571.1 MPa); this is because that, for the composite with aligned MWCNTs, there are more MWCNTs preventing the shear deformation in the shear plane, which can lead to a high modulus. For this, we can refer to Figure 8. The modulus $M^{\prime}$ got a maximum when the composite was at glass transition temperature, at which the macromolecular chains began to move actively, and a constant shear force can only cause a little deformation. After that, the composite came in an elastomeric state, and the modulus tended to be stable with a small value. We usually treat the temperature at which the curve of loss factor $\tan \delta$ has a peak as the glass transition temperature $\left(T_{g}\right)$. It was found that the alignment of MWCNTs made $T_{g}$ of composite with $10 \mathrm{vol}$.
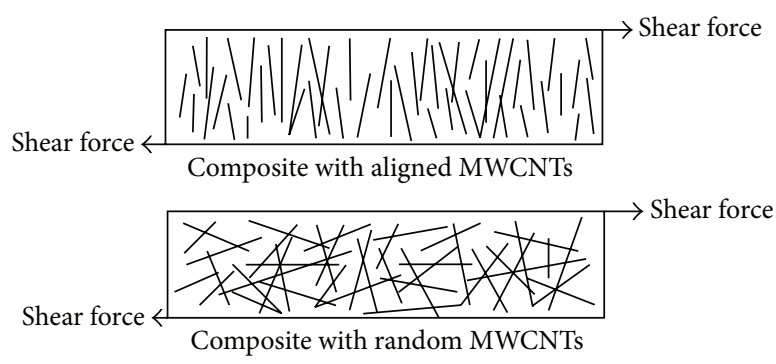

FIgURE 8: Samples for DMA test.

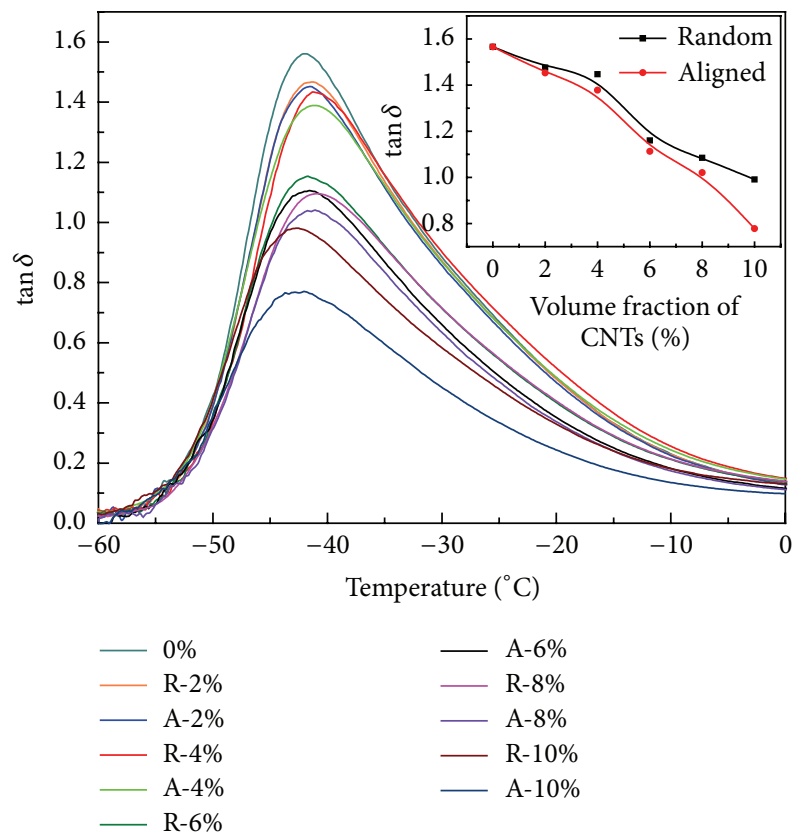

FIGURE 9: $\tan \delta$ of composite with various MWCNTs concentration before and after alignment.

$\%$ of MWCNTs decrease from $-42.5^{\circ} \mathrm{C}$ to $-43.0^{\circ} \mathrm{C}$. This indicates that the random MWCNTs would provide more physical crossing points which lead to a stronger network preventing the movement of molecular chains. The resulting dynamic mechanical behavior for each sample was shown in Table 3, and we can see the same variation trend for a certain volume fraction of composite. The curves of $\tan \delta$ for composite with various CNTs concentration were shown in Figure 9, where "A" is for composite with aligned CNTs and " $\mathrm{R}$ " is for composite with random CNTs. It was found that the addition of 2 vol. \% of MWCNTs and more into the NR matrix caused a considerable downward shift which was enlarging with the filler concentration. It means that CNTs will contribute to the mechanical stiffness and strength of natural rubber, which has been observed by other authors $[36,37]$. And the alignment could always decrease the loss factor perpendicular to the axis of the alignment. 


\section{Conclusion}

This work presents a new methodology to fabricate a natural rubber composite with aligned MWCNTs. Two steps were needed in the procedure; first, prepare a mixture latex of natural rubber, MWCNTs, and other components. Then orient the carbon nanotubes by a flow field. This was achieved by compelling the latex to pass through a sieve with holes by pressure. The alignment of MWCNTs in the matrix has been confirmed by both transmission electron microscope and Raman spectroscopy. The thermal conductivity of composite with aligned MWCNTs has been increased greatly due to the priority of heat transfer along the axis of carbon nanotubes. It can expand the application areas of natural rubber widely combined with its excellent mechanical properties. Through the dynamic mechanical analysis, we found that the alignment of MWCNTs can increase the storage modulus of composite at glassy state dramatically due to more MWCNTs in the shear plane preventing the shear deformation, which can lead to a high shear modulus. And the alignment of MWCNTs made $T_{g}$ of composite decrease, which indicates that the random MWCNTs would provide more physical crossing points which lead to a more strong network preventing the movement of molecular chains.

\section{Conflict of Interests}

The authors declare that there is no conflict of interests regarding the publication of this paper.

\section{Acknowledgments}

The experimental research and the instrumentations used were partially financed by NSFC (Natural Science Foundation of China), project name: Study on Thermal Conductivity Mechanism and Structure-Activity Relationship of Carbon Nanotubes/Rubber Composite Material, Project no. 51276091. It was also funded by Shandong Science and Technology Agency by the project Study on Industrialization and Application of New Carbon Materials, whose Project no. is 2014ZZCX01503. The authors acknowledge the support from the Center of Analysis and Measurement in Beijing University of Chemical Technology for the polarization Raman tests.

\section{References}

[1] S. Iijima, "Helical microtubules of graphitic carbon," Nature, vol. 354, no. 6348, pp. 56-58, 1991.

[2] T. W. Ebbesen, H. J. Lezec, H. Hiura, J. W. Bennett, H. F. Ghaemi, and T. Thio, "Electrical conductivity of individual carbon nanotubes," Nature, vol. 382, no. 6586, pp. 54-56, 1996.

[3] J. Zuo, W. Yao, and K. Wu, "Seebeck effect and mechanical properties of carbon nanotube-carbon fiber/cement nanocomposites," Fullerenes, Nanotubes and Carbon Nanostructures, vol. 23, no. 5, pp. 383-391, 2015.

[4] H. Zanin, H. J. Ceragioli, A. C. Peterlevitz, V. Baranauskas, F. R. Marciano, and A. O. Lobo, "Field emission properties of the graphenated carbon nanotube electrode," Applied Surface Science, vol. 324, pp. 174-178, 2015.
[5] A. E. Aliev, C. Guthy, M. Zhang et al., "Thermal transport in MWCNT sheets and yarns," Carbon, vol. 45, no. 15, pp. 28802888, 2007.

[6] S. K. Peddini, C. P. Bosnyak, N. M. Henderson, C. J. Ellison, and D. R. Paul, "Nanocomposites from styrene-butadiene rubber (SBR) and multiwall carbon nanotubes (MWCNT) part 1: morphology and rheology," Polymer, vol. 55, no. 1, pp. 258-270, 2014.

[7] P. Wang, S. Geng, and T. Ding, "Effects of carboxyl radical on electrical resistance of multi-walled carbon nanotube filled silicone rubber composite under pressure," Composites Science and Technology, vol. 70, no. 10, pp. 1571-1573, 2010.

[8] P. Kueseng, P. Sae-Oui, C. Sirisinha, K. I. Jacob, and N. Rattanasom, "Anisotropic studies of multi-wall carbon nanotube (MWCNT)-filled natural rubber (NR) and nitrile rubber (NBR) blends," Polymer Testing, vol. 32, no. 7, pp. 1229-1236, 2013.

[9] S. Berber, Y.-K. Kwon, and D. Tománek, "Unusually high thermal conductivity of carbon nanotubes," Physical Review Letters, vol. 84, no. 20, pp. 4613-4616, 2000.

[10] P. Kim, L. Shi, A. Majumdar, and P. L. McEuen, "Thermal transport measurements of individual multiwalled nanotubes," Physical Review Letters, vol. 87, no. 21, Article ID 215502, 2001.

[11] Y. Hwang, M. Kim, and J. Kim, "Improvement of the mechanical properties and thermal conductivity of poly(ether-etherketone) with the addition of graphene oxide-carbon nanotube hybrid fillers," Composites-Part A: Applied Science and Manufacturing, vol. 55, pp. 195-202, 2013.

[12] D. G. Cahill, W. K. Ford, K. E. Goodson et al., "Nanoscale thermal transport," Journal of Applied Physics, vol. 93, no. 2, pp. 793-818, 2003.

[13] H. Huang, C. Liu, Y. Wu, and S. Fan, "Aligned carbon nanotube composite films for thermal management," Advanced Materials, vol. 17, no. 13, pp. 1652-1656, 2005.

[14] Q. Wang, J. Dai, W. Li, Z. Wei, and J. Jiang, “The effects of CNT alignment on electrical conductivity and mechanical properties of SWNT/epoxy nanocomposites," Composites Science and Technology, vol. 68, no. 7-8, pp. 1644-1648, 2008.

[15] M. Zhang, S. Fang, A. A. Zakhidov et al., "Strong, transparent, multifunctional, carbon nanotube sheets," Science, vol. 309, no. 5738, pp. 1215-1218, 2005.

[16] F. Lionetto, E. Calò, F. Di Benedetto, D. Pisignano, and A. Maffezzoli, "A methodology to orient carbon nanotubes in a thermosetting matrix," Composites Science and Technology, vol. 96, pp. 47-55, 2014.

[17] S. Kumar, H. Kaur, H. Kaur, I. Kaur, K. Dharamvir, and L. M. Bharadwaj, "Magnetic field-guided orientation of carbon nanotubes through their conjugation with magnetic nanoparticles," Journal of Materials Science, vol. 47, no. 3, pp. 1489-1496, 2012.

[18] S. Wu, R. B. Ladani, J. Zhang et al., "Epoxy nanocomposites containing magnetite-carbon nanofibers aligned using a weak magnetic field," Polymer, vol. 68, pp. 25-34, 2015.

[19] B. Vigolo, A. Pénicaud, C. Coulon et al., "Macroscopic fibers and ribbons of oriented carbon nanotubes," Science, vol. 290, no. 5495, pp. 1331-1334, 2000.

[20] Z. Zhang, S. Tang, and Y. Wang, "Momentum and flow field analysis of tiny-hole Jet-flow in high-pressure homogenization processing," Packaging and Food Machinery, vol. 23, pp. 5-7, 2005.

[21] Z. Chen, Y. Yang, Z. Wu et al., "Electric-field-enhanced assembly of single-walled carbon nanotubes on a solid surface," Journal of Physical Chemistry B, vol. 109, no. 12, pp. 5473-5477, 2005. 
[22] J. Hone, M. C. Llaguno, N. M. Nemes et al., "Electrical and thermal transport properties of magnetically aligned single wall carbon nanotube films," Applied Physics Letters, vol. 77, no. 5, pp. 666-668, 2000.

[23] D. W. Kang and S. H. Ryu, "Orientation of carbon nanotubes in polypropylene melt," Polymer International, vol. 62, no. 2, pp. 152-157, 2013

[24] C. Zamora-Ledezma, C. Blanc, N. Puech et al., "Conductivity anisotropy of assembled and oriented carbon nanotubes," Physical Review E, vol. 84, no. 6, Article ID 062701, 5 pages, 2011.

[25] J. H. Lehman, M. Terrones, E. Mansfield, K. E. Hurst, and V. Meunier, "Evaluating the characteristics of multiwall carbon nanotubes," Carbon, vol. 49, no. 8, pp. 2581-2602, 2011.

[26] N. Romyen, S. Thongyai, and P. Praserthdam, "Alignment of carbon nanotubes in polyimide under electric and magnetic fields," Journal of Applied Polymer Science, vol. 123, no. 6, pp. 3470-3475, 2012.

[27] M. Abdalla, D. Dean, M. Theodore, J. Fielding, E. Nyairo, and G. Price, "Magnetically processed carbon nanotube/epoxy nanocomposites: morphology, thermal, and mechanical properties," Polymer, vol. 51, no. 7, pp. 1614-1620, 2010.

[28] M. Lamy de la Chapelle, C. Stéphan, T. P. Nguyen et al., "Raman characterization of single-walled carbon nanotubes and PMMA-nanotubes composites," Synthetic Metals, vol. 103, no. 1-3, pp. 2510-2512, 1999.

[29] F. F. T. De Araujo and H. M. Rosenberg, "The thermal conductivity of epoxy-resin/metal-powder composite materials from 1.7 to 300 K," Journal of Physics D: Applied Physics, vol. 9, no. 4, article 017, pp. 665-675, 1976.

[30] J.-P. Song, Y. He, and L.-X. Ma, "Percolation behavior in thermal conductivity of carbon black filled rubber," Journal of Engineering Thermophysics, vol. 32, no. 4, pp. 641-644, 2011.

[31] Y. Hwang, M. Kim, and J. Kim, "Improvement of the mechanical properties and thermal conductivity of poly(ether-etherketone) with the addition of graphene oxide-carbon nanotube hybrid fillers," Composites Part A, vol. 55, pp. 195-202, 2013.

[32] J. Hong, J. Lee, C. K. Hong, and S. E. Shim, "Effect of dispersion state of carbon nanotube on the thermal conductivity of poly (dimethyl siloxane) composites," Current Applied Physics, vol. 10, no. 1, pp. 359-363, 2010.

[33] I. N. Mazov, I. A. Ilinykh, V. L. Kuznetsov et al., "Thermal conductivity of polypropylene-based composites with multiwall carbon nanotubes with different diameter and morphology," Journal of Alloys and Compounds, vol. 586, no. 1, pp. S440-S442, 2014.

[34] H. Mei, H. Wang, N. Zhang, H. Ding, Y. Wang, and Q. Bai, "Carbon nanotubes introduced in different phases of $\mathrm{C} / \mathrm{PyC} /$ $\mathrm{SiC}$ composites: effect on microstructure and properties of the materials," Composites Science and Technology, vol. 115, pp. 2833, 2015.

[35] T. Ogasawara, S.-Y. Moon, Y. Inoue, and Y. Shimamura, "Mechanical properties of aligned multi-walled carbon nanotube/epoxy composites processed using a hot-melt prepreg method," Composites Science and Technology, vol. 71, no. 16, pp. 1826-1833, 2011.

[36] S. Rooj, A. Das, K. W. Stöckelhuber et al., “'Expanded organoclay' assisted dispersion and simultaneous structural alterations of multiwall carbon nanotube (MWCNT) clusters in natural rubber," Composites Science and Technology, vol. 107, pp. 36-43, 2015.

[37] L. Tzounis, S. Debnath, S. Rooj et al., "High performance natural rubber composites with a hierarchical reinforcement structure of carbon nanotube modified natural fibers," Materials and Design, vol. 58, pp. 1-11, 2014. 

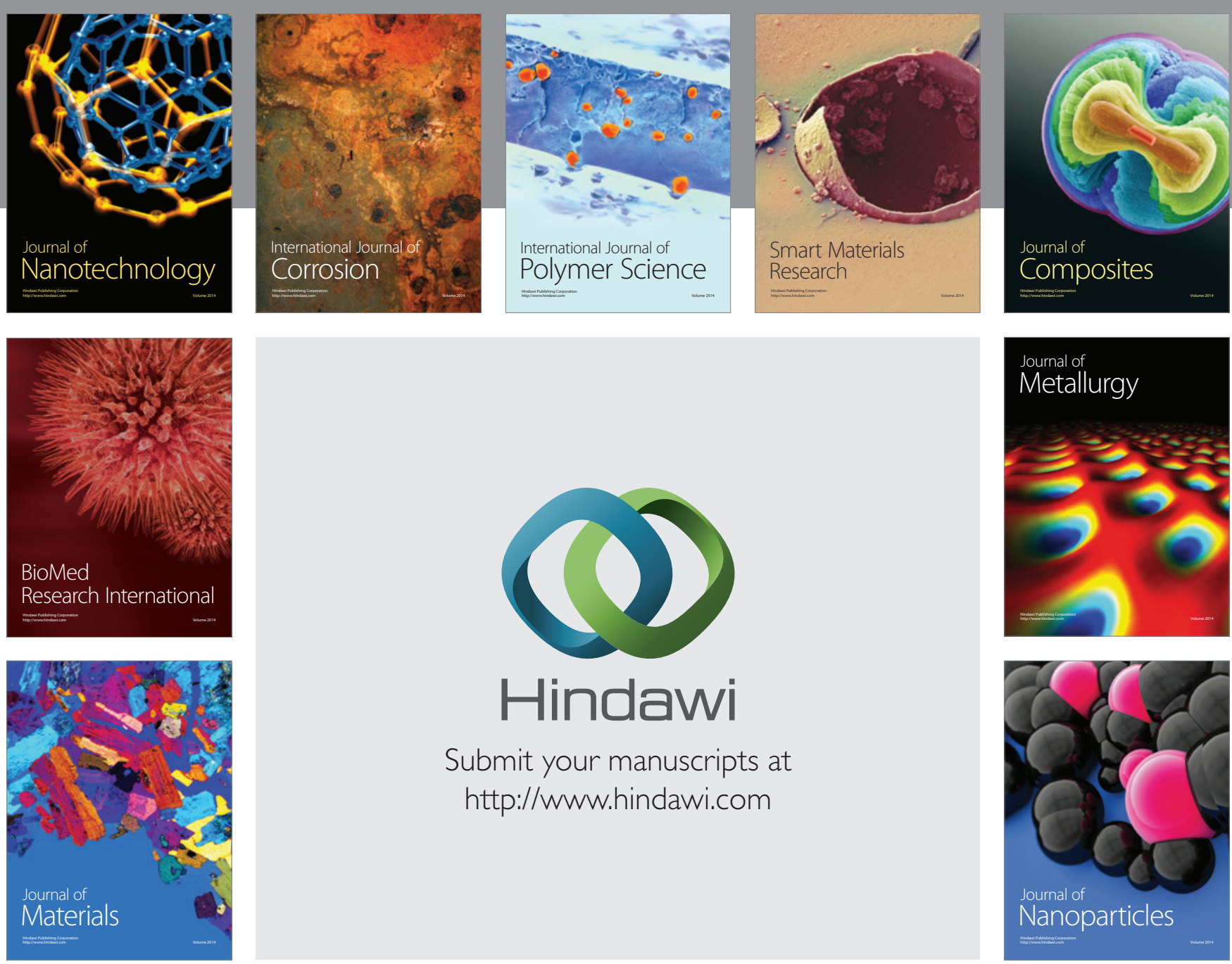

Submit your manuscripts at http://www.hindawi.com
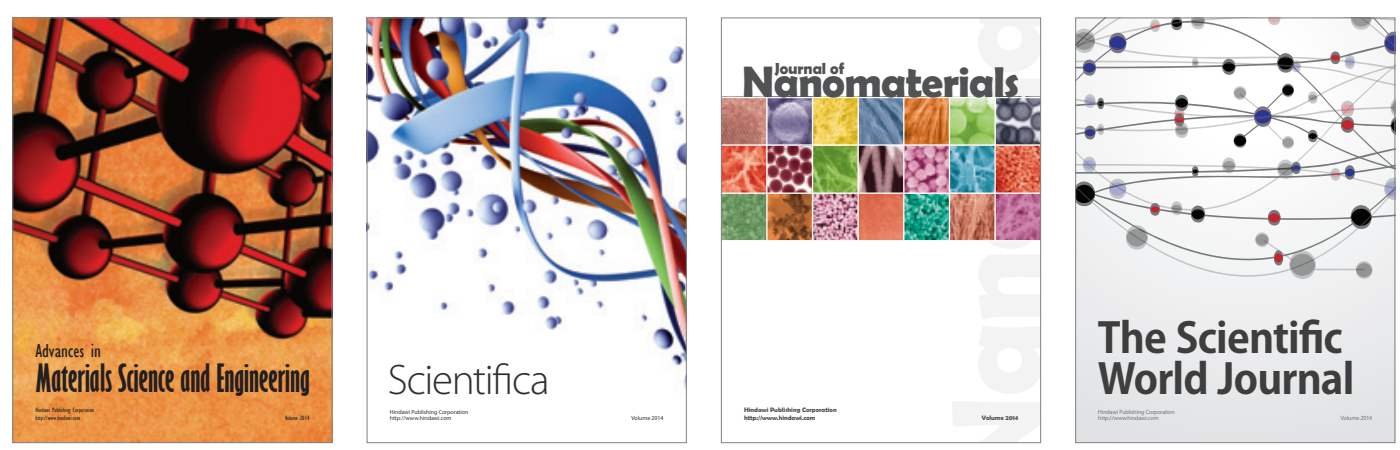

\section{The Scientific World Journal}
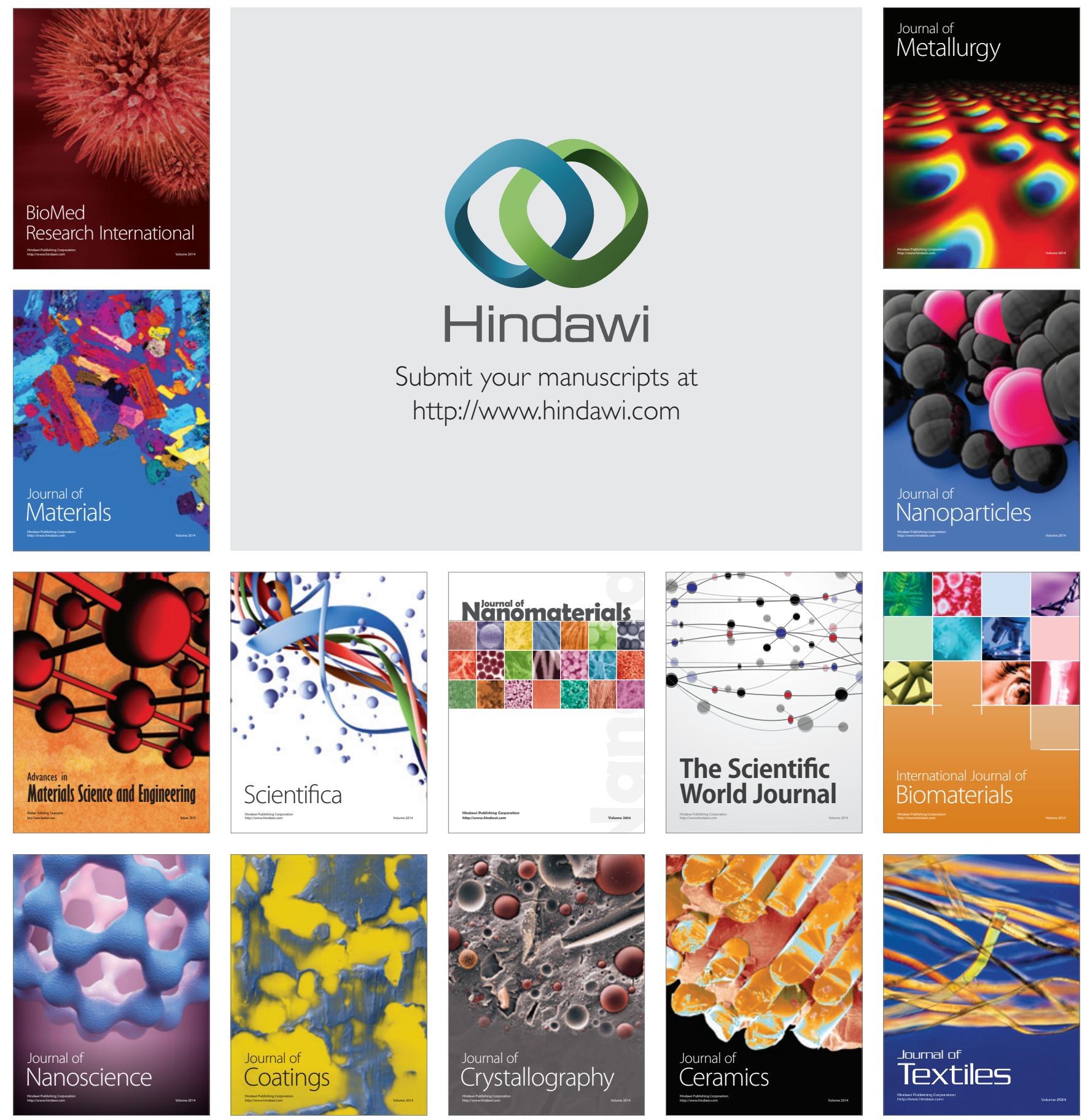